Article

\title{
How to Constitute a Field of Merit: Structure and Flexibility in a Tibetan Buddhist Monastery's Curriculum
}

\section{Dominique Townsend}

Department of Religion, Bard College, 30 Campus Rd, Annandale-on-Hudson, NY 12504, USA; dtownsend@bard.edu

Received: 17 August 2017; Accepted: 23 August 2017; Published: 7 September 2017

\begin{abstract}
The written curriculum of Tibet's prestigious Mindrölling monastery, composed in 1689, marries a firm pedagogical structure with flexibility for individual students. This reflects the monastery's balance of institutional priorities, shaped by its religious, cultural, and political climate. The curriculum's author was Terdak Lingpa, a charismatic visionary and systematizer of the "Ancient" or Nyingma school of Tibetan Buddhism who forged alliances with the Fifth Dalai Lama's government in Lhasa starting in the seventeenth century. As part of Mindrölling's formal constitutional document, the curriculum commits students and teachers to a distinctive approach to Buddhist training and helps to constitute the monastery and its members as a Buddhist "field of merit." As such, Mindrölling is presented as a worthy recipient of support and protection from patrons and of respect from the community. The curriculum reflects a variety of overarching priorities for a relatively diverse student body over time and therefore calls for individual flexibility within a reliable and sustainable institutional structure. In this way, the curriculum demonstrates Mindrölling's identity as a bridge between the potentially competing values of the Tibetan Buddhist schools of the author's day.
\end{abstract}

Keywords: Tibet; Buddhism; curriculum; Nyingma; pedagogy; performative

\section{Introduction}

As part of a special issue of Religions, this article engages the themes of "pedagogy" and "performance" in order to analyze the brief (three-page in modern book format) curriculum of a Tibetan Buddhist monastery called Mindrölling (smin grol gling). The monastery was founded in 1670 by Terdak Lingpa (gter bdag gling pa, 1646-1714). As a renowned Buddhist master and charismatic visionary, he is Mindrölling's central authority figure and the curriculum's author. Terdak Lingpa was a close student of and eventual advisor to the Fifth Dalai Lama Nawang Lobsang Gyatso (ngag dbang blo bzang rgya mtsho, 1617-1682) and his regent Desi Sangye Gyatso (sde srid sangs rgyas rgya mtsho, 1653-1705). These two powerful figures sponsored the founding of Mindrölling.

The curriculum of study and practice is found within a longer document called a chayik (bca' yig), which has been published in a history of Mindrölling entitled O rgyan smin grol gling gi dkar chag (Bstan pa'i sgron me 1992). ${ }^{1}$ Scholars working on similar texts have translated the Tibetan genre term chayik with terms including "legal document," "constitution," "constitutional document," "guidelines," and "charter" (Ellingson 1990; Cabezón 1997; Jansen 2015, 2016; Sur 2017). All these terms have merits. ${ }^{2}$

1 An appendix to the original constitutional document is also included in the monastic history (Bstan pa'i sgron me 1992, pp. 317-39).

2 In her excellent survey of the genre, Jansen convincingly argues for "guidelines" as the most generally relevant rendering of $b c a^{\prime}$ yig in English (Jansen 2015, 2016). 
I use the term "constitutional document" in order to draw attention to how the formal written text functions to "constitute" or construct Mindrölling's institutional identity.

The constitutional document provides a wealth of information about life at Mindrölling monastery. It addresses issues of concern to members of the monastic community as well as to potential patrons and critics. In addition to outlining the curriculum of study, it presents rules about dress code, visits from family members, relations with neighboring villagers, the monastery's ritual calendar, and punishments for rule infractions. It provides details about fines, including the number of butter lamps monks must pay for, the amount of tea students must provide for the other monks, and physical acts of penance such as performing full-body prostrations and doing manual labor around the monastery if one breaks the rules. Such regulations apply to all members of the community, and the constitutional document overall does not attend to exceptions or options for particular individuals.

I focus here on the brief section that summarizes the monastic curriculum rather than analyzing the entire document. The curriculum section succinctly articulates the content and style of education at Mindrölling and is therefore particularly pertinent to the themes of this special issue. The curriculum demonstrates the pedagogy Terdak Lingpa designed for Mindrölling and directs teachers and students to engage in a prescribed and reproducible system of education (Bourdieu and Passeron 1990; Townsend 2012). The curriculum stands out from the longer constitutional document in the degree to which it balances a carefully designed structure of study with flexibility for the individual student.

As a means of approaching the issue's other theme of "performance," I employ a theory of performance formulated by J.L. Austin in his seminal work, How to Do Things With Words, to interpret the curriculum as a contractual agreement. In keeping with Austin's usage, I use "performative" here to mean statements that do something rather than merely saying something (Austin 1975). Some illustrative examples of performative speech acts are, "I now pronounce you husband and wife," and "I owe you twenty dollars." When such statements are made by a person with relevant authority under appropriate circumstances, the words change the nature of the relationships of the people involved. In general cases like marriage and debt, words establish social commitments that oblige the people implicated to behave in a certain manner, or else break the contractual agreement. ${ }^{3} \mathrm{I}$ argue that this is also the case in the specific context of Terdak Lingpa's curriculum. (This specific use of "performative" does not suggest pretense, dissimulation, or theatricality.)

Terdak Lingpa, as Mindrölling's founder and principal authority figure, is an appropriate person to create a contract for the community at Mindrölling. ${ }^{4}$ Terdak Lingpa uses the constitutional document to lay out the guidelines for members of Mindrölling and to define the aims and characteristics of the Mindrölling community. He uses performative language in the specific "contractual" sense I have just outlined to constitute Mindrölling's institutional identity and to create a binding agreement between the various members of Mindrölling. This contractual agreement commits the community to follow Terdak Lingpa's instructions and thereby accomplish the two-fold aim of (1) cultivating Buddhist awakening and (2) serving the broader community.

By Terdak Lingpa's time, composing a constitutional document was a well-established Tibetan Buddhist convention for constituting and regulating a community, and Terdak Lingpa makes sophisticated use of the genre's possibilities. Through the curriculum-as-contract, Terdak Lingpa explicitly engages members of the monastery to study and practice what he prescribes and to adhere to his pedagogy. In order for the performative act crystallized in the document to be successful,

3 Austin states that in order for a speech act to qualify as performative: (A.1) There must exist an accepted conventional procedure having a certain conventional effect, that procedure to include the uttering of certain words by certain persons in certain circumstances, and further, (A.2) the particular persons and circumstances in a given case must be appropriate for the invocation of the particular procedure invoked. (B.1) The procedure must be executed by all participants both correctly and (B.2) completely. (Austin 1975, pp. 14-15).

4 Ellingson indicates that it was often the case that an outside authority was invited to compose a monastery's constitutional document (Ellingson 1990, p. 209). This was not the case at Mindrölling. 
members of Mindrölling for their part would have to execute Terdak Lingpa's directions correctly and completely.

The curriculum's performative language specifically commits Mindrölling's current and future members to pursue certain Buddhist goals-awakening and generating an abundance of merit (the stuff of good karma). According to the premise of the document, by cultivating Buddhist awakening, members of the Mindrölling community become a font of goodness and virtue for lay supporters, who can participate in the community's merit by offering Mindrölling their patronage. Thus, implicitly, the curriculum also creates a contractual agreement with potential patrons by demonstrating that Mindrölling is genuinely worthy of respect and support.

How members of the Mindrölling community should cultivate awakening and become a worthy "field of merit" is described painstakingly in the constitutional document. The curriculum section notably uses a distinctive pedagogical method that integrates structure and flexibility in equal doses. This flexibility, together with the markedly successful contractual performativity of the constitutional document, is one of Terdak Lingpa's great accomplishments. It has enabled the document to remain relevant and helped the Mindrölling community more broadly to flourish into the present day.

In order to uphold the curriculum's contractual claim that Mindrölling and its members should be a genuine field of merit, the institution needed to be many things to many people. In particular, it needed to be a place for celibate monks to train in discipline, an exemplar for large scale ritual, a haven for extreme renunciants engaged in meditation practice, and the site of learning and high culture associated with the ruling class. Its role as an exemplar of "Ancient" or Nyingma (rnying ma) school teachings and highly visible ritual practice simultaneously had to accommodate the norms being set by the Dalai Lama's dominant "Virtuous Way" (dge lugs) or Geluk school, which emphasizes celibacy and scholasticism.

\section{Continuity and Context Sensitivity}

Today, the community is marked by relative continuity tempered by contextual adaptations. This was made possible in part by Terdak Lingpa's curriculum, where he successfully lays out a reproducible structure that nonetheless maintains flexibility for the individual and context. ${ }^{5}$ Mindrölling's institutional identity was shaped by the complex soteriological, cultural, economic, and political factors active in late seventeenth century Central Tibet. At the same time, key aspects of its institutional identity have remained consistent over time, while necessarily allowing for adaptation due to time and place. Mindrölling continues to be a significant and vibrant institution today. The original center created by Terdak Lingpa is located in Central Tibet. There is also a major monastery in Dehradun, India, a thriving center in the US, as well as affiliated sites throughout the Tibetan cultural region. I argue that the seeds of Mindrölling's long-term survival can be found in Terdak Lingpa's structural vision for the monastery, one that is evident in his curriculum. As I will show, Terdak Lingpa creates a reproducible structure that nonetheless maintains flexibility for the individual.

For example, today at the branch of Mindrölling monastery in Dehradun, India, the highest degree holders or khenpos (mkhen po) are still familiar with Terdak Lingpa's constitutional document and curriculum, although they also employ contemporary guidelines in running the monastery. The learned teacher Khenpo Tsegyal keeps the book close at hand in his personal library. He recently indicated that no one has the authority to replace the founder's constitutional document, although aspects of the rules have been amended and revised for practical reasons over time. He explained the monastery still follows Terdak Lingpa's curriculum in its "essential points." However, he acknowledged that the rules and curriculum have had to be adapted, for instance to attend to shifts in climate, food,

5 Jansen's comment that bca' yig are "not necessarily written to stand the test of time" (Jansen 2015, p. 20) may hold generally, but in the case of Mindrölling Terdak Lingpa's lasting authority and the community's perception of him as having special insight render the document authoritative over time, even while allowing for pragmatic adaptations. 
and modern social norms. So, for example, the monks now have weekends off from classes, and they are given official certificates at the culmination of their studies similar to a diploma from a more conventional school. He also mentioned practical changes in the rules about monastic robes, food, and the number of texts that the monks must memorize. Today, monks are allowed to bring texts into the temple to read aloud when they do large-scale rituals ( grub chen) for which Mindrölling is renowned. By contrast, in Terdak Lingpa's day, monks were required to learn all the ritual texts by heart (Interview with (Tsegyal 2017)). ${ }^{6}$

Lama Gyurme, a former monk who was trained with a specialty in visual arts at the Mindrölling monastery in Central Tibet, likewise described a notable adherence to the original 1689 curriculum in his training. The continuity was punctuated by isolated changes, such as monks being required to memorize fewer ritual texts (Gyurme 2016). ${ }^{7}$ Such changes and adaptations do not overshadow the extent to which Mindrölling still adheres to the vision Terdak Lingpa articulated in the constitutional document-the monastery still focuses on cultivating excellence in its specific style of ritual practice, in the literary arts, and in an esoteric system of meditation and philosophy called Great Perfection (rdzogs chen).

The specific seventeenth-century context in which Mindrölling was founded demanded the balance of structure and flexibility that we find in the curriculum section of the constitutional document. The curriculum shows Mindrölling to be a place that harmoniously balances potentially contradictory Buddhist values and pursuits, some of which were being contested sharply among the Tibetan Buddhist schools of Terdak Lingpa's time. These include celibacy and lay practice, renunciation and worldly learning, religion and politics, and scholasticism and esoteric meditation. It is important that Terdak Lingpa's approach proved to be reproducible over time since the system of education he established at Mindrölling would shape the tastes, deportment, sense of self, and worldview of generations of students, in turn helping to perpetuate Tibetan hierarchies of religious and cultural authority.

The curriculum also reflects underlying questions about what kind of education was useful for Mindrölling's particular student body during Terdak Lingpa's time. The community was made up principally of celibate monks whose training was the main subject of the curriculum. There was also a smaller group of nuns affiliated with the monastery. This arrangement has been reproduced at the Mindrölling center in India, where the monks' center and quarters is in Dehradun and the nuns' residence is in nearby Mussoorie. In addition to monks and nuns living within their respective communal settings, in Terdak Lingpa's time, there were also meditators practicing in solitary retreat near Mindrölling and occasional elite lay aristocrats studying at the monastery. All of these factors are discernible in the curriculum.

On the cultural front, seventeenth-century Tibetan Buddhist literati debated a related epistemological question about how to prioritize the formal subjects of worldly or secular learning in relation to religious learning. These subjects fall within the Indian category of the five rikné (rig gnas) or "fields of knowledge" and include medicine, grammar, logic, and arts and crafts in addition to the study of Buddhism. A secondary list of five additional rikné subjects includes astrological calculation, poetics, composition, the study of synonyms, and drama. Over Buddhism's long history, scholars have grappled with the question of where worldly learning should fit into the hierarchy of knowledge. In Terdak Lingpa's time, the Dalai Lama's Geluk school discouraged the study of secular subjects in monasteries since they were seen as competing with one's study of Buddhism (Dreyfus 2003; Townsend 2016). And yet, it was necessary for Tibetans of the ruling class to be cultured, knowledgeable, and articulate in order to achieve and maintain power. But how should they develop such skills when monasteries were the centers of learning, and when it was widely accepted that

\footnotetext{
Interview conducted in June, 2017, in Clement Town, Dehradun, India.

Interview conducted over the telephone in November, 2016. Lama Gyurme was in Santa Fe, New Mexico and I was in New York.
} 
religious knowledge must be prioritized over worldly knowledge? Mindrölling helped fill this void and became a center for excellence in these subjects, especially the literary arts, namely composition, poetics, and grammar (Bstan pa'i sgron me 1992, p. 176) and astrological calculation.

Terdak Lingpa also had to contend with a tenuous political reality in constructing his monastic curriculum. In particular, he had to appeal to the tastes of a diverse set of interests outside of the monastery itself. For instance, how to approach the Buddhist ideal of joint political and religious power (chos srid zung 'brel) embodied in the role of the Dalai Lama, as the leading "Virtuous Way" or Geluk school, was not simple to achieve, in theory or practice. Terdak Lingpa's collected letters demonstrate that he was confident in advising his colleagues and students in this regard, further testimony to his adroitness in reconciling apparent tensions (Gter bdag gling pa 1977). Appealing to the tastes and values of official sponsors who might support the monastery was also a concern for Terdak Lingpa, especially given the shifting political climate in which various Buddhist schools vied for power in tension with Mongol and Qing powers.

Social mores were also an important consideration, particularly for the Nyingma school of which Mindrölling is a part. The school held the cultural capital of having been the first Buddhist tradition established in Tibet, but its tantric practitioners also had a long history of being accused of corrupting the Buddhist teachings. This was due largely to associations with a shift away from celibate monasticism to lay practice, and concerns about practitioners using alcohol and engaging in esoteric sexual practices (Karmay 1998; Dhondup 2013, p. 130; Sur 2017). The stakes were high for Mindrölling to meet the expectations of supporters of the dominant Geluk school, while maintaining the traditions and practices for which the Nyingma school was renowned.

In short, Terdak Lingpa's lifetime was a cosmopolitan moment that called for diplomacy, keen political rhetoric, and demonstrable steeping in Buddhist high culture. In his curriculum's structured yet flexible outline of study and practice at Mindrölling, Terdak Lingpa attended to these demands of his context. In doing so he was also successful in creating a monastic system that would stand the tests of time. Taking up Austin's theoretical framework, I argue that Terdak Lingpa's curriculum acts as a textual performance through which the monastery and its members are constituted as a Buddhist "field of merit," meaning a place where people attain Buddhist awakening and a worthy object of support and protection. Because of the particular climate in which Mindrölling was founded, the pedagogy had to be both structured and flexible in order for the place to qualify as a worthy field of merit.

\section{Conceptualizing a "Field of Merit" in Seventeenth-Century Tibet}

To further elaborate on the context in which Terdak Lingpa composed the curriculum and the other part of the document that helped constitute Mindrölling, it is important to stress that there was a great deal at stake in the performance of being genuine "field of merit." The concept is rooted in the Pali Canon in which the Buddhist community is divided into four parts: laymen, laywomen, monks, and nuns. The ordained male and female members of the community dedicate themselves to Buddhist practice, thereby becoming a worthy "field of merit" to be supported by Buddhist laypeople. The relationship is reciprocal since the ordained generate merit for the benefit of all, and the laity gain merit by supporting the ordained. This is important since merit accumulates into good karma. According to Bhikkhu Bodhi:

By accepting the gifts of lay people, the monastics give them the opportunity to acquire merit. Since the volume of merit generated by the act of giving is said to be proportional to the worthiness of the recipient, when the recipients are the Buddha and those following in his footsteps, the merit becomes immeasurable ... For this reason, the sāvakasangha, the spiritual community of noble disciples, is called, "the unsurpassed field of merit for the world" (Bodhi 2005, pp. 152-53). 
What it means to "follow in the footsteps" of the Buddha, or to be perceived as a fully awakened person similar to the Buddha, looks different in different Buddhist settings, as Gregory Schopen's abundant work has shown (e.g., Schopen 2004). The concept of the monastery as a worthy recipient of support by the laity is foundational to the ideal of a mutually supportive relationship between the ordained and the lay members of society. What was at stake was rooted in the model formed during Buddhism's earliest period in India-the ordained monks and nuns should be fertile fields were good karma and even enlightenment were generated on behalf of the whole community, including the laymen and laywomen who were engaged necessarily in less meritorious acts than monks and nuns. These acts include marriage, sex, parenthood, etc. Such activities were closely related to anxieties around the danger of Nyingma practitioners being seen as corrupt and not "virtuous" enough to fulfill the expectations of the Dalai Lama's Geluk school.

\section{Terdak Lingpa and Mindrölling Monastery}

Terdak Lingpa and his relatives made up a branch of the prominent Tibetan aristocratic family group known by the name Nyö (gnyos or myos). Families such as theirs had held joint political and religious authority in Central Tibet since at least the twelfth century (Sorensön and Hazod 2007, p. 381). For that reason, Mindrölling's founder could offer advice and guidance for the Dalai Lama in his role as joint religious and political ruler (Townsend 2016). Simply put, Terdak Lingpa recognized the value of both worldly and religious education. As an essential conduit of Tibetan Buddhism's Nyingma school, Terdak Lingpa's lineage of teaching and practice was passed down via familial relationships. ${ }^{8}$ The Mindrölling lineage functions similarly to a monarchy, with the role of the principle throne-holder (khri chen) being passed from parent to child. As throne-holders, Terdak Lingpa and his successors are not fully ordained monks but rather ritual experts and Buddhist masters who are also householders. The centrality of family relationships in the Mindrölling lineage is reflected subtly in the attention within the curriculum to diverse types of students with different paths and inclinations, examined below.

Terdak Lingpa's family also had strong ties to the early modern central Tibetan government, which was run by members of the Geluk school. Most importantly for the founding of the monastery, Terdak Lingpa was close with the most powerful Geluk school leaders, the Fifth Dalai Lama and his regent Desi Sangye Gyatso. The regent arguably was as impactful as the Dalai Lama himself, and his connections to Mindrölling were as significant. These Geluk figures were dedicated to consolidating centralized authority led by the Dalai Lama as religious and secular ruler over the greater Tibetan cultural region, with significant if incomplete success. Modeled on the longstanding Buddhist ideal of joint religious and secular rule, theirs was a major early modern state-building project (Gyatso 2015). Terdak Lingpa, the Fifth Dalai Lama, and regent Sangye Gyatso remained intimately involved in each other's affairs throughout their lives.

Terdak Lingpa was brought into the circle of the Fifth Dalai Lama as a young boy, as the son of a noble woman and a famous master of Great Perfection. The Dalai Lama at that time was already established formally as the religious and political ruler of Tibet and was in the ongoing process of attempting to consolidate Tibetan identity and his authority over it, often contentiously through forceful or coercive means (Schaeffer 2013), as well as by many creative state building endeavors. Both Terdak Lingpa and the Dalai Lama (who had family ties to the Nyingma school and other Tibetan schools beyond his own official Geluk affiliation) recounted visionary experiences that indicated the significance of the other in the state building project of the newly established central government of Tibet (Dudjom Rinpoche 1991).

8 Reincarnation and teacher to student transmissions of authority are also employed at the monastery, but the family relationship has remained essential. 
The extremely powerful Fifth Dalai Lama and his regent both looked to Terdak Lingpa as an advisor, despite his relative youth. This is apparent through analysis of the letters they exchanged. For example, the Fifth Dalai Lama compared Mindrölling, as an extension of Terdak Lingpa, to a grove of wish-fulfilling trees that serve as a refuge for "greater Tibet" (bod chen) (Ngag dbang blo bzang rgya mtsho 1975). Further, the regent corresponded with Terdak Lingpa about generating a systematic calendrical system, organized around the Buddhist rituals for which Mindrölling became famous (Gter bdag gling pa 1977; Dalton 2016).

Terdak Lingpa was also cultivated from his boyhood as a Great Perfection master under the tutelage of his father, who was the hierarch of Dargye Chöling (dar rgyas chos gling) an important center for Great Perfection philosophy and meditation in the central Tibetan region prior to the founding of Mindrölling, which later took over that role (Cuevas 2003). Great Perfection meditation and philosophy is designated as the "highest" form of meditation practice by its practitioners and patrons. To be perceived as a Great Perfection master entails significant charisma and authority.

As a young man, Terdak Lingpa became renowned as a visionary revealer of hidden teachings and practices (gter ston). This is an important Tibetan Buddhist category. Such masters are understood to have special access to Buddhist teachings that were concealed centuries ago so that they could be unearthed at the appropriate time. This vibrant and innovative revelatory tradition is known as the Tibetan tradition of terma (gter ma), widely translated in English as "treasure." The texts that emerge through the revelatory experiences of the visionaries who discover them often are objects of suspicion and debate as well as immense religious and cultural authority in Tibetan Buddhist communities. Mindrölling became a prestigious center for Nyingma learning and practice based in part on Terdak Lingpa's expertise and renown as a treasure revealer.

Terdak Lingpa engaged across sectarian divides with many of the most influential Tibetan Buddhist teachers of his day while successfully securing the institutional foundation of the Nyingma school. He is described consistently in biographical materials as radically unbiased (ris med), a descriptor that signifies not only "nonsectarian" as it is rendered typically today. Rather, the term suggests something along the lines of "panoramic" in his perspective. This suggests a philosophical and existential state that is without fixed orientation, spacious and open, without clinging to one's personal perspective. Such a state is strongly associated with the Great Perfection philosophy and mediation practice. He also successfully systematized the Nyingma school's textual foundations and ritual practices in a highly visible and influential manner (Dalton 2002, 2016). Terdak Lingpa was a renaissance man, who exemplified a mastery of arts and aesthetic forms as well as a cosmopolitan attitude and at the same time stood as a paragon of Buddhist ideals of renunciation and realization.

During this vibrant yet deeply tumultuous period, some Tibetan monasteries affiliated with schools other than the Dalai Lama's Geluk school were forced for political reasons to convert to the Geluk system. By contrast, the Dalai Lama and his regent directly supported and oversaw the founding of Mindrölling as a center for Nyingma practices and large-scale rituals that also fit within the Geluk vision of a good monastery. Throughout his writing, Terdak Lingpa stressed the importance of the combined mastery of religious and worldly knowledge (lugs gnyis). This was closely tied to the ideal of the Dalai Lama's multifaceted position as ruler. In this regard, Mindrölling's role as a school for the Central Tibetan aristocratic ruling class is noteworthy. Some of the most prominent members of the ruling class studied religious and worldly subjects at the monastery for two to three years before entering into government or military service (Townsend 2016). Many influential aristocratic families, such as Dokar (Do khar) and Polha (Po lha), identified with the Nyingma school and patronized Nyingma institutions. For those powerful families, an education at Mindrölling or under Mindrölling-trained tutors provided the prestigious credentials to secure a good career in the Dalai Lama's government. In many cases, and up to the twentieth century, elite families sent their children to be educated at the monastery prior to taking up positions of power in the government since Mindrölling was a respected center for Nyingma religious practice as well as cultivation in the worldly arts and knowledge. 
The monastery also became an important model for other Nyingma monasteries across the Tibetan Buddhist world, especially in regard to the ritual arts. As just one significant example, the Nyingma institutions in the vital intellectual center of Rebkong, in the Amdo region of Eastern Tibet, were all established directly on the Mindrölling model (Dhondup 2013). The lengthy list of "branches" and affiliated monasteries is documented in the Mindrölling history (Bstan pa'i sgron me 1992, pp. 153-60).

In sum, Terdak Lingpa was by birth, education, and perhaps temperament well situated to forge a bridge between competing values and visions of his day. Mindrölling is the materialization of the special if not unique position that he occupied. The monastery he created had to be both structured and flexible to meet the demands of his day.

\section{The Genre of Tibetan chayik (bca' yig)}

Most large Tibetan Buddhist monasteries, many small local monasteries, and even in some cases, groups of students devoted to a particular teacher, all have constitutional documents. Berthe Jansen's dissertation entitled "The Monastery Rules: Buddhist Monastic Organization in Pre-Modern Tibet" provides an invaluable survey of a range of such documents, reflecting the breadth and practical utility of the genre. Her work reveals that chayiks make up a significant, if difficult to define, genre of Tibetan literature and provides a rich source of information pertinent to the study of religion and social history. Such documents act as manifestos, proclaim rules and regulations, state the monastery's purpose, project its future, outline the daily life of its inhabitants (including dress, food, discipline, how to deal with illness, etc.), describe the ideal relationship with the monastery's surrounding community, and in some cases list branch and affiliate monasteries (Jansen 2015). Constitutional documents are extremely useful in providing material about Tibetan Buddhist life and history beyond the stated religious ideals that appear in more widely studied genres of Tibetan writing.

Based on the Mindrölling example, I argue that constitutional documents can also work as contractual agreements between the institutional authority, the members of the monastic community, the wider society, and potential patrons. While these are not contracts that must be followed to the letter, such constitutional documents do set up clear expectations for how to behave, clarify the purpose for behaving in the prescribed way, and prescribe what to do if those expectations are not met. In this way, constitutional documents define the monastery's identity and define what it means to be a part of that particular community. Such documents arguably are more important for their monasteries than the monastic code of the vinaya, which in most cases (including at Mindrölling) is only studied peripherally, and only by advanced students (Dreyfus 2003; Schopen 2007; Jansen 2015).

Jansen's research shows that Tibetan schools treat these documents in very different ways, ranging from the secretive and even magical to the public and mundane (Jansen 2015, p. 33). In the case of Mindrölling, the constitutional document has been treated as context sensitive, allowing for "overwrites" that adapt to changes in time and place, and yet maintain the document's fundamental authority because Terdak Lingpa composed it. The constitutional document is reproduced in the modern publication of a history of Mindrölling, thus attesting to its lasting authority. Learned members of the contemporary Mindrölling community assert that the original document is still respected, despite the practical changes that have been made.

In many cases, the "outward facing" intentions of constitutional documents are significant. In other words, although they directly address the "insider" members of the particular monastery or group, the documents can also address an "outside" audience beyond the particular monastic community, for example to give the laity a sense of how the monks should be expected to behave (Jansen 2016, p. 82; Sur 2017, p. 14). Many such documents are publicly performed, for instance read aloud by the monastery's disciplinarian, sometimes with proverbs added for illustration (Jansen 2016, p. 83). Others are displayed prominently on the monastery walls. Jansen also recounts that some monasteries do not allow anyone but the relevant monastic authorities to see the documents. In particular, the Geluk school tends to guard its guidelines as secret, whereas other monastic communities allow outsiders to read them (Jansen 2015, p. 32). 
Terdak Lingpa was not explicit about the intended audience for the constitutional document and curriculum, but the accessible language and tone suggest that he allowed for the possibility that the document might be consulted by readers beyond Mindrölling. The curriculum seems to both direct the students and teachers regarding how to cultivate awakening, as well as to indicate to patrons and the community what to expect from members of Mindrölling. Terdak Lingpa's flexible structure invites continuity while allowing for adaptation. Mindrölling's contractual constitutional document thus allows for adaptation over time and addresses both insider and outside audiences. These characteristics situate Mindrölling at the edge of Jansen's definition of the genre, but are nevertheless in keeping with her findings. This sheds light on the connection between Terdak Lingpa's efforts to cultivate the monastery and its members as a field of merit to his commitment to creating a curriculum of study and practice characterized by structure and flexibility. These efforts were directed both inward to the students and teachers and outward to potential sponsors.

\section{Summary of the Curriculum}

This section presents a paraphrased summary of the curriculum section of the constitutional document. (In the following section I present key excerpts of the translated text with analysis.) The curriculum's balance of structure and individual flexibility will become apparent through this overview.

First, study and contemplation are established as the root cause of Buddhist awakening. After entering the monastery, students should rely on their teachers and avoid becoming lazy or spoiled. Students must cultivate correct bodily deportment in all activities. They should begin by studying reading, rituals, and doctrine without becoming intellectually rigid. In accordance with individual capacity, they should take in as many lessons as possible. With the exceptions of periods of travel or sickness, students should meet with teachers every day and study as much as they are capable. Students and teachers must develop a mutual sense of responsibility in the highest aspiration of Buddhist awakening. In keeping with each individual's capacity, the three-part examinations should be passed within five years. The examinations can be undertaken incrementally or all at once. Teachers and students must not remain indifferent to the student's progress. If examinations are not passed successfully after fifteen years (Bstan pa'i sgron me 1992, p. 287), penalties are to be exacted from the student (in the form of extra manual labor) and the teacher (in the form of a large number of lamp offerings) alike. After sixteen years, if examinations have not been passed, the student alone is responsible for bearing the penalty. The institutional authorities should decide the appropriate course of action. Teachers must uphold the decisions of previous authorities in regard to student progress, even as rotating positions of power change hands.

Students should develop specialties in keeping with each individual's intellectual approach. They should gain mastery of visualization techniques and ritual practices as appropriate for the particular student. They should become skilled in the ritual arts of melodies, chanting, making offerings, mandalas, and dancing, all of which are particularly significant for Mindrölling. They should become self-reliant in all the relevant activities. When performing rituals, they should be involved actively and exercise care, not sitting silently or behaving clumsily as if they have donkey hooves for hands. In keeping with the individual student's approach, they should gain independent mastery of the Secret Essence Tantra (Sanskrit: Guhyagarbha) cycle, the central tantric system of Mindrölling. Through memorizing the words and understanding the meaning, receiving instructions, explanations, and listening to teachers, the student should attain the position of a scholar. In regard to highest capacity students, they should study a suitable amount of monastic discipline, Perfection of Wisdom teachings, and the philosophical system. As much as possible, those of the highest capacity should 
study the other fields of knowledge as much as they are capable. ${ }^{9}$ This knowledge is the armor that will safeguard the student's essential goals and it must not be allowed to fall away. The teacher must not remain indifferent to the arousal of the student's altruistic attitude. Seasonal routines of study should be observed: in summer and winter, tantra is the focus; in spring and autumn, prātimokṣa and bodhisattva vows, empowerments, oral instructions, and whatever will lead to the individual student's liberation are the focus (Bstan pa'i sgron me 1992, p. 288). In particular, the vows should be studied every day, sharpening the student's understanding of what behaviors to adopt and what to abandon.

Those who are interested in the "development stage" of meditation practice, should spend at least six months engaged in the practice most appropriate for that student, according to whichever text is suitable given the chosen deity, such as the Fierce and Peaceful Guru Padmasambhava, (bla ma zhi drag), the Great Compassion (thugs rje chen po, a Mindrölling practice manual or sādhanā discovered as a treasure by Terdak Lingpa), the Magical Display, (sgyu 'phrul), and The Eight Pronouncements, (bka' brgyad), Kilaya (phur ba), and Yamantaka (gshin rje gshed). By means of continuous meditation and recitation, students should train the body, perception, and mind as the pure vision wheel of wisdom. Students should do the practice of the Twenty-eight Samayas (dam tshig nyer brgyad), unerring in the distinctions between the objects of meditation and their various aspects.

If a student is principally engaging in the "completion stage" of meditation practice, they should focus on the two Heart Essence (snying thig) teachings, the Vajra Bridge, (rdo rje zam pa) and the instructions on the newly revealed treasure teachings (gter gsar), following whichever experiential instruction is appropriate according to one's personal experience. Having participated in the confession ritual with all of its elements, students should be thorough so as not to allow misdeeds to have lasting consequences

In regard to solitary retreat practice, for those of highest capacity, staying within the community of monks and going into solitary retreat are equivalent. Solitude is better in general for generating virtue, but for those of middling and lower capacity, remaining in the monastic community is preferable. If one cannot even manage to give up drinking beer or eating an evening meal, one should certainly not be in solitary retreat. In brief, this should be a genuine community of monks. Students who do go to the mountains to engage in solitary retreat must continue to observe the monastic rules while in retreat. When students return to the community of monks, they should not be too carefree in talking and thinking about retreat; they should not cultivate discord in the community. ${ }^{10}$ Based on rigorous study, contemplation, and meditation, individual students and Mindrölling as a community should become a field of merit, worthy of praise (Bstan pa'i sgron me 1992, p. 289).

\section{Analysis of the Curriculum}

In his concise curriculum as paraphrased above, Terdak Lingpa does the following: (1) establishes a long-term reproducible course of study and practice for the monastery, (2) provides flexibility for individual students of varying inclinations and capacities, (3) demonstrates Mindrölling and its members' integrity as a Buddhist "field of merit" that meets the virtuous standards of the Geluk school, and (4) simultaneously demonstrates an attitude of spontaneity and individuality that is characteristic of the Great Perfection philosophical and meditative system, for which Terdak Lingpa's Nyingma lineage was famous. To accomplish all these aims was not a simple task, and the curriculum demonstrates a delicate but confident balancing act of institutional priorities.

9 The category of rig gnas or "fields of knowledge" includes religion (chos) as well as the four "other" principal fields of worldly learning that Terdak Lingpa refers to here.

10 The term which I'm translating as "carefree" is gu yangs which might also be translated as "spacious" or "free." In a Great Perfection practice context, this is a very positive characteristic and would generally be considered praise. In this passage, however, Terdak Lingpa seems to use it in a critical sense, to demonstrate that one can misapply such an attitude. 
The first section of the curriculum summarized above outlines basic training and deportment for monks who have recently entered the monastery. The guidelines become more specific as the curriculum progresses, attending to various ritual arts, fields of worldly learning, and areas of meditative expertise that students might develop to varying extents. It culminates in a strongly stated proclamation about the guidelines to weigh when considering solitary meditation retreat beyond the monastery's walls.

The curriculum takes as its starting point the claim that, "study and contemplation are the basis for awakening" (Bstan pa'i sgron me 1992, p. 287). It ends with a directive, aimed at the monastic body: "In brief, through the activities of studying, contemplating and meditating day and night, heavy with the weight of learning, discipline and nobility, become a field of merit, worthy of praise by the wise" (Bstan pa'i sgron me 1992, p. 289). To cultivate the monastic community as a field of merit is among the most ubiquitous normative claims across Buddhist societies and is a commonly stated aim of constitutional documents (Ellingson 1990, p. 212). These opening and closing statements frame the fundamental, albeit general, aims of education at the monastery, to be accomplished by means of study, contemplation, and meditation (thos, bsam, sgom), according to the individual student's capacity.

Throughout the curriculum, there is a frequent articulation and reiteration along the lines of, "In keeping with the individual's capacity for understanding..." This flexibility is built into the progressive structure of training, examinations, and potential areas of expertise. The regularity of this language in the curriculum section is distinct from the rest of the constitutional document, which rarely allows for individual circumstances or capacities in laying out the guidelines for good behavior and punishment for infractions. Within the curriculum, this sentiment of flexibility for the individual exemplifies the monastery's pedagogical approach. It is implied that while awakening and being a field of merit should be the ultimate aim, the fact is students are diverse and not everyone has the same capacity nor inclinations. This sentiment is phrased and rephrased in various ways throughout the course of study, setting the tone for the contractual language that defines the curriculum. While phrases such as "as much as one is capable" (ci nus su) or "in keeping with one's own intellectual approach" (rang rang gi blo gros kyi 'jug sgo dang sbyar ba'i) and so forth are not unusual in and of themselves, Terdak Lingpa generates a striking tone by frequent reiteration. Phrases of this general type occur more than a dozen times within the three page curriculum.

Indeed, almost every stage of education outlined in the curriculum is followed by a phrase that indicates the particular training must be based on the inclinations and capacity of the individual student. Even without engaging in a comprehensive comparison of this curriculum to similar Tibetan monastic curricula (a worthwhile project beyond the scope of this article), this feature of the curriculum sets a distinctive tone that expresses a distinctive pedagogical method. It is as if a college professor were to compose a course syllabus (also a kind of informal contract with the enrolled students, administrators, and those who might patronize or criticize the college) with an addendum of "as appropriate for the individual student" balancing every element of the assigned course material. The approach is neither free-form nor rigid, but rather a systematic balance of step by step training, with each step punctuated by the acknowledgement that the particular path must be determined based on the student's capacity, interests, talents, inclinations, and context. Terdak Lingpa could have simply made one statement about the need for attention to the individual at the beginning and end of the curriculum, but instead he interweaves that requirement into every stage of the educational process. This leaves the impression that Terdak Lingpa was committed to a pedagogy that allowed for the particular needs of students, while creating a stable framework.

The attention to diversity might come as a surprise to readers who are unfamiliar with Buddhist education. Such a reader might assume that the goal and path for all members of a Buddhist monastery are identical. Mindrölling's curriculum clearly demonstrates that this was not its founder's expectation or intention. In fact, catering to a diverse monastic body is by no means unique to Mindrölling. To some extent, all Buddhist monasteries in all times and places have generated a variety of roles for different types of people-for a few examples, some are administrators, some philosophers, 
some artists, some disciplinarians, and some are meditators. However, beyond the basic diversity of monks based on inclinations and capacities, the question of diversity would have been especially salient at a monastery like Mindrölling, where the head lamas are not fully ordained monks but rather ritual experts, charismatic visionaries, and scholars who can and do marry and have children. Moreover, as mentioned previously, while the majority of students in the Mindrölling community were monks, some were nuns, and a very few were lay aristocrats from the highest echelon of Tibetan society who attended the monastery for a brief time to train in a variety of religious and worldly subjects. The curriculum uses a general term for "student," (slob ma) and does not refer to monks, nuns, or lay students specifically. It is probable that the curriculum was primarily intended for monks. However, other biographical and historical literature about Mindrölling attests to the fact that laypeople also studied there, and their potential presence at any given time further underscores the need for an atmosphere of flexibility.

As reflected in the summary above, the curriculum is concerned with cultivation of the students' holistic way of being in the world, their attitudes, dispositions and demeanor, in keeping with Bourdieu's theory of habitus (Bourdieu 1977). Terdak Lingpa starts by setting the basic parameters for training at the monastery, establishing standards of deportment and intellectual qualities (not being lazy and not being rigid), and setting the rigorous tone of the curriculum (students should be tested every day and take in as many lessons as they are capable of).

Looking more closely, the section begins with the statement that "study and contemplation" (thos bsam) are the main basis for enlightenment and connects this basic aim to the development of the correct attitude in students:

Principally, since the primary cause of the accomplishment of awakening depends on study and contemplation, after having initially joined the monastery, in general students should not develop negative mental habits nor become spoiled (Bstan pa'i sgron me 1992, p. 287).

This attention to study and contemplation (here distinct from meditation practice which comes later in the curriculum) is significant. It indicates that intellectual learning is essential for achieving Buddhist awakening. The opening statement undermines a commonly held assumption that training in the Nyingma school is focused on meditative practice at the expense of scholarly pursuits. This attention to study subtly signals Mindrölling's relationship with the Dalai Lama's Geluk school, which emphasizes scholasticism (Dreyfus 2003), but is also rooted in the family lineage's long history of engaging in both religious and secular education (lugs gnyis).

The question of to what extent all students were expected to actually achieve the highest goal of awakening is complicated by the attention to a variety of individual paths indicated throughout the curriculum. Although awakening is presented as the ultimate aim, overall it would seem that the students deemed to have "middling" and "lower" capacities might not be expected to achieve awakening. This indicates in part that Terdak Lingpa acknowledged just how difficult the project of awakening is. The fact is most students won't accomplish that goal, which underscores why flexibility is essential to the curriculum, and why Terdak Lingpa so attentively reiterates the importance of attending to the individual. And yet being part of a community where that is the unifying ideal is crucial for cultivating the monastery and its members as fields of merit, worthy of praise. Again, the demand for structure that supports the fundamental aims shared by all needed to be tempered by the reality of different student capacities. All members of the community, whether the most famous visionaries bound for full awakening, or those monks struggling to pass the examinations after sixteen years of training, could and must contribute to the potential for the monastery to be cultivated to its fullest potential.

It is clear that all entering students at the monastery should avoid negative mental habits and should not become spoiled or lazy. The text then directs students to rely on the monastic hierarchy of teachers and authority figures for guidance in the most basic aspects of physical deportment. The attention to deportment is common in Buddhist monastic constitutions, which generally are 
concerned with providing guidelines on how to behave. The importance of positive mental and physical habits is presented as being a basic necessity. This attention to students' modes of behaving and carrying themselves suggests that the "whole person" was being cultivated in a way that was structurally integrated and reproducible over time. Behaving properly and carrying oneself with dignity and respect would be the baseline for fulfilling the contractual agreement of the curriculum.

Students should begin with training in modestly practicing all the four modes of conduct. ${ }^{11}$ From there, practicing reading aloud, ritual, dharma practice, and so forth, the mind must not become rigid but deeply clear and pure through skillful instruction. In accordance with the conditions of each individual's understanding, grasp as many daily text lessons as one is able (Bstan pa'i sgron me 1992, p. 287).

The curriculum refers to a hierarchy of teachers who oversee the training and development of the students in the early phases of training (i.e., before they have passed the examinations). Although the teachers' specific duties are not the main focus of the curriculum, there is indirect reference to the fact that their roles rotated on a prescribed schedule, some taking up the position of tutor of a large group of students, others overseeing individual progress, and still others acting as disciplinarians. No specific information is provided in regard to how students were assigned their particular teachers, for how long they studied with any given tutor, or to what extent instruction took place in groups versus individually.

Disciplining the physical body is coupled with attention to the quality of the student's mind through contact with the teacher: "the mind not becoming rigid but deeply clear and pure though skillful instruction" (Bstan pa'i sgron me 1992, p. 287). What follows is the first individualized directive: "In accordance with the conditions of each individual's understanding ... " It continues:

... with the exceptions of periods of travel for monastic duties, illness, and so forth, regular text lessons should be given and received every day without fail, as much as can be managed, similar to the example of an anthill and honey (i.e., with intense focus and tireless enthusiasm). Both master and student should generate a sense of responsibility in producing the highest aspiration (Bstan pa'i sgron me 1992, p. 287).

Training at Mindrölling requires a mental state that is vigorous and disciplined, but not rigid. So on the one hand, laziness and idleness are to be avoided, and on the other hand, one is trained ideally to remain supple-minded. This call for balance between rigor and suppleness resonates with Buddhism's Pali canon, in which frequent analogies are made between the mind and a well-tuned musical instrument. This is also in keeping with the distinctive Great Perfection attitude of an active but relaxed and open or even "panoramic" state of mind. Here again is an expression of the structure and flexibility of the curriculum - for students of all capacities, the mind should be disciplined in adherence with the structure delineated, but not in a manner that might become overly strident or fixed.

Next, Mindrölling's three-part system of examinations is outlined. The examinations are required for all students at the early phase, to ensure that they are prepared for more advanced and individualized study.

In accordance with the student's intellectual condition, the examinations can either be given collectively or the three-part examination series can be given incrementally. Whichever approach is taken, the examinations must be passed within five years. It is not acceptable if both (teacher and student) remain indifferent ... (Bstan pa'i sgron me 1992, p. 287).

11 These are eating, walking, sitting, and lying down. 
While the general limit for the examinations was established as five years, the curriculum goes on to explain what should be done if the exams are not passed in fifteen or sixteen years. The individual student's capabilities determine how long it takes to prepare for the examinations, how they structure the actual examination process, and what the consequences are if the student fails. If after fifteen years the student has failed to pass the examinations, both teacher and student are punished; teachers are required to offer butter lamps and students must do menial labor. After sixteen years the penalty for failing examinations falls on the student alone (Bstan pa'i sgron me 1992, p. 288). ${ }^{12}$

This suggests that during Terdak Lingpa's time, not all students passed the examinations, and therefore potential failure was an issue that required attention. The curriculum states that the teacher must maintain a sense of determination and urgency in training students. Both teacher and student are held accountable for the student's progress or failure. This is an important indicator of Mindrölling's pedagogy - demonstrating that all members of the community are expected to take responsibility for the cultivation of the students and the community overall, in the project of generating a field of merit.

After the examinations are completed, education becomes even more specialized to the individual. The next part of the curriculum establishes specific courses of study and practice, indicating particular rituals, stages of meditation, and texts appropriate for various types of student, from the highest caliber to those incapable of observing the most basic guidelines. The following are some examples of the sentiment of "in keeping with the individual's capacity..."

On the importance of learning to engage in visualization practices central to tantric Buddhism (by which the practitioners uses the imagination to see him or herself as identical with an enlightened Buddha), the curriculum states:

After that, in accordance with each individual's intellectual approach, one should study and contemplate to become deeply self-reliant in the visualization stage of the appropriate ritual practice (Bstan pa'i sgron me 1992, p. 288).

In regard to internalizing Mindrölling's main esoteric Buddhist textual and ritual system, primarily through memorization and analysis:

Then, in accordance with each respective student's approach to understanding, study the detailed commentary and the general essence of the Secret Essence Tantra, the pedagogical exegesis which constitutes the stable center of our system (Bstan pa'i sgron me 1992, p. 288).

On various classical systems of Buddhist learning, based in Indian Buddhist tradition, the best students are singled out from the rest, suggesting again that not all students should follow the same path:

Regarding those of the highest capacity, they should study a suitable amount of Vinaya, the Perfection of Wisdom teachings and so forth, and the philosophical vehicle's system (Bstan pa'i sgron me 1992, p. 288).

And especially important for Mindrölling, which was vital as a place of "worldly learning," the curriculum states:

(Those of the highest capacity) should also study the other fields of knowledge (rig gnas), as much as they are capable. This is the armor that protects one essential goals and must not be allowed to fall away (Bstan pa'i sgron me 1992, p. 288).

All the excerpts above continue to build on the overall structure while allowing for individual paths. There are a few especially noteworthy sections. First, the attention to intellectual development

12 The content of the three-part examinations is not mentioned explicitly. During an interview with Lama Gyurme, he indicated that the examinations mainly tested students' ability to memorize the assigned texts. 
and knowledge of worldly fields of study suggests that the relevant knowledge would be a crucial protection or "armor" that students should rely on in attaining their future aims. Creating a parallel to "become a field of merit," the curriculum states, "attain the position of a scholar." The metaphor of knowledge as armor is a telling and significant choice on Terdak Lingpa's part. It is crucial to note that both worldly and religious learning are included in the scope of the classical Buddhist fields of knowledge. In regard to the directive to study worldly subjects, the curriculum acknowledges that knowledge is power, or at the very least protection from harm (i.e., "armor"). As mentioned above, the proper approach to studying the fields of knowledge was a hotly debated topic among Tibetan Buddhists of Terdak Lingpa's day (Townsend 2016). The curriculum makes it clear that studying worldly fields of knowledge (alongside Buddhist doctrine) was essential to education at Mindrölling and therefore essential to the ideal goals of awakening and becoming a field of merit. These fields of study were emphasized for the students with the highest capacity.

Also noteworthy is the reiterated attention to teachers' and students' attitudes, which should not be lax or "indifferent." In particular, Terdak Lingpa insists that teachers should not take up the attitude, "it's all the same to me." Instead, he commands the teachers to recognize that their students' progress matters immensely. He encourages them to see the opportunity to guide students in the "highest aspiration" of awakening must not be squandered: "Both master and student should generate a sense of responsibility in producing the highest aspiration" (Bstan pa'i sgron me 1992, p. 288).

The curriculum's focus on the ritual arts is also significant. Notably, in this regard Terdak Lingpa does not mention individual paths, suggesting that all students at the monastery should take the ritual arts seriously. This is important since Mindrölling is renowned for excellence in maintaining ritual arts of all aesthetic varieties (visual, audial, olfactory, etc.). All these rituals are associated with offerings designed to appeal to the senses of the deities, based on Terdak Lingpa's insights. (Khenpo Tsegyal insisted that what makes Mindrölling's rituals special is Terdak Lingpa's pure insight, not the perceived "beauty" of the rituals.) Terdak Lingpa makes special note of this type of ritual arts training:

As for melodies, chanting, instrumentation, offerings, mandalas, lama dances and so forth, don't remain idly donkey-handed or silent during rituals. These are to be internalized genuinely as indispensable aspects of the activities to be maintained in our particular monastery (Bstan pa'i sgron me 1992, p. 288).

This passage suggests that ritual training is especially important at Mindrölling. Furthermore, it shows that not all members of Mindrölling took this aspect of their education seriously. Some must have engaged a clumsy, "donkey-handed" manner, sitting silently when they should be chanting the memorized texts. It was crucial that students learned proper performance of ritual arts. In fact, Mindrölling's reputation and prestige in the Tibetan Buddhist world were established in part thanks to large public rituals that took place at the monastery, attracting high profile patrons and practitioners from across the Tibetan Buddhist area (Dalton 2016). This resonates with the focus on deportment already mentioned, and reiterates the particular significance of behaving well during rituals for which the monastery was renowned.

Terdak Lingpa next established a basic seasonal schedule to attend to different facets of study and practice. This further demonstrates that the curriculum was meant to lay the foundation for future generations to study at Mindrölling. At the same time, he paid attention to the needs of the individual, calling for "whatever will lead to one's own" awakening:

In both summer and winter practice sessions, the explanation of the tantras should be studied and contemplated. In both the autumn and spring practice sessions, request the prātimokșa and bodhisattva vows, together with empowerments, instructions, oral transmissions, direct instructions, and whatever will lead to one's own ripening and liberation (Bstan pa'i sgron me 1992, p. 288).

Terdak Lingpa next addresses meditation practice, offering an array of paths for individuals. He directs "those who are interested in the development stage" (Bstan pa'i sgron me 1992, p. 289) 
to proceed in one of a variety of ways, engaging the appropriate text focused on an appropriate deity for the appropriate amount of time (at least six months). Those students engaged in the more advanced "completion stage of meditation" should engage in "whatever experiential instruction is appropriate based on one's personal experience" (Bstan pa'i sgron me 1992, p. 289). For both generation and completion stages, he lists texts that are of special significance to Mindrölling's Great Perfection tradition.

The most striking and extensive section of the curriculum reflects on the question of whether students should leave the monastery to engage in solitary meditation retreat. This appears to have been a vexed question at the time of the curriculum's composition, given the critical tone and the relative length of the discussion. Again, Terdak Lingpa demonstrates a pedagogical method of creating a structure that allows flexibility for the individual:

For the highest caliber individual, community and solitude are the same. Solitude is best for increasing virtue, however, for middling and lower caliber individuals who stay in an isolated place, the mind is not disciplined. Left to their own devices, they lose control to laziness and idleness. Some even turn out to be unable to give up intoxicants and evening meals (Bstan pa'i sgron me 1992, p. 289).

Terdak Lingpa develops this theme of whether to engage in solitary retreat more elaborately than any of the other stages of education in the curriculum. The attention the subject received suggests that there was some disagreement about how to determine who should go into retreat. Terdak Lingpa sets this straight. The text also indicates that those who are in retreat must continue to follow the monastic guidelines, suggesting that some retreatants did not adhere to the rules.

More subtly, the curriculum directs students to refrain from going on and on about how great retreat is once they return to the community setting:

Become a genuine community of monks that gathers in harmony with the doctrine. Perform activities in keeping with the teachings. Given the accomplishment of the marvelous two purposes (of benefitting self and other), having become discouraged by the gathering of monks, do not be overly carefree in talking and thinking about retreat (Bstan pa'i sgron me 1992, p. 289).

Terdak Lingpa seems to have wished to settle the question of who should engage in solitary retreat-only the best students, and only if they follow the rules and do not disrupt the community when they return. This suggests a distinction between members of the community engaged in more conventional monks' roles within the monastery walls and those who were engaged in solitary retreat. These represent two types of Buddhist discipline: the celibate monastic and the tantric yogic (Mills 2010). Terdak Lingpa's discouraging tone suggests that some unqualified (i.e., middling and lower caliber) students wanted to engage in retreat, and that some qualified students who did solitary retreat did not uphold the monastic rules. This might indicate that engaging in solitary retreat carried a high degree of prestige in the Mindrölling community, as well as an opportunity to get out of the mundane duties of monastic life.

Practically speaking, the monastery needed all kinds of practitioners in order to function as a place of learning, ritual, contemplation, and enlightenment. It needed great ritual experts as well as great meditators. In short, Mindrölling needed students to fulfill their appropriate roles in order for the monastery to fully realize Terdak Lingpa's stated aim of cultivating a field of merit. Finally, the curriculum ends with the fundamental institutional and soteriological aim, to cultivate a field of merit through study, contemplation, and meditation:

In brief, through the activities of studying, contemplating, and meditating day and night, heavy with the weight of learning, discipline and nobility, become a field of merit, worthy of praise by the wise (Bstan pa'i sgron me 1992, p. 289). 
These examples demonstrate the pervasive attention Terdak Lingpa's curriculum paid to the individual's way of learning and capacity in determining the appropriate approach to each stage of education. At the same time that an ethos of flexibility is established, a structured course of study is specified. After passing the foundational examinations, the curriculum lays out a variable training in visualization practice, the ritual arts, the monastery's principal tantric system, the classical fields of knowledge, monastic vows, bodhisattva vows, development and completion stage practices, and, for the most qualified members of the community, solitary retreat practice.

Thus the curriculum demonstrates the Mindrölling pedagogy in a brief yet detailed manner, addressing matters of both method and content. Terdak Lingpa's explicit intention with this approach to education is to cultivate awakening and to render the monastic body and its individual members as worthy recipients of patronage and protection. Based on the teachers' and students' adherence to the contractual agreement of the curriculum, the broader Buddhist community should offer material support, respect, and protection to the monastery and its members. If Mindrölling and its members are genuinely worthy, the act of offering this support and protection in turn generates "merit" (the stuff of good karma) for the broader community.

\section{Conclusions}

Terdak Lingpa was in the complicated position of establishing a stable and respectable institution that would preserve the vital aspects of his Nyingma school and meet the approval of members of the dominant Geluk school. He had to consider a diverse range of Tibetan, Mongol, and Qing patrons and critics vying for power on the Tibetan political stage. His era was a time of political and sectarian tumult as well as one of early modern Tibetan state-building and systematizing. This was true not only for members of the Geluk school that controlled the central Tibetan government, but also for members of Mindrölling, who sought to systematize their own Nyingma school's practices while supporting the Fifth Dalai Lama's efforts to create the religious, political, social, and cultural mechanisms for a unified Tibetan state. The Mindrölling curriculum subtly reflects those aspects of the broader historical context.

The curriculum is remarkable for its balance of formal reproducible structure integrated with flexibility for individual students and context. These overarching characteristics of structure and flexibility encompass a set of productive tensions that were and are central to Tibetan Buddhist identity and discourse beyond Mindrölling. These include the tensions between politics and religion, scholasticism and meditative experience, communal and solitary practice, monastic renunciation and yogic renunciation, formal discipline and spontaneous experience, and celibate monasticism and lay tantric practice. Through its simultaneous structure and flexibility, the curriculum contains these underlying tensions, which are productive and need not be reconciled. These tensions are embedded in distinctions between the Geluk school and the Nyingma school. On the one hand, the Geluk school is characterized by celibate monasticism, strong institutions, and scholasticism. On the other hand, the Nyingma school is valued for maintaining the oldest tantric teachings and practices of Buddhism in Tibet, with ties to the Tibetan empire, but is also critiqued for laxity and continually suspected of corruption.

Why was it necessary for Terdak Lingpa's curriculum to address different paths for different individuals? Because, despite commonly held stereotypes of all Buddhists as meditators, different types of Buddhist practitioners engage in radically different Buddhist practices, some of which appear to be in direct contrast to one another. For instance, a tantric practitioner who is not ordained as a monk or nun might engage physically in sexual yoga, whereas monks and nuns vow to maintain celibacy. Or, some monks might be suited to solitary meditation retreat beyond the walls of the monastery, whereas others would be better suited to doing ritual practice within the monastery, with the support of the community. A subtext of the curriculum is how to become an enlightened person free of fixations and attachments while also being in the world as a functioning and cultured member of society.

In order to meet the expectations of the dominant Geluk school, a rigorous attention to formal monasticism was essential. At the same time, the mentality of the Great Perfection philosophy for 
which the Terdak Lingpa and his family were famous valorizes open-mindedness and spontaneous experience. In sum, as a school for Central Tibet's ruling class elite, an exemplary center for Nyingma rituals, a training ground for Great Perfection, a refuge for celibate monks and nuns, and a launching site for tantric yogins entering solitary retreat, structure was necessary to prevent disorder, and flexibility was necessary to allow for the branching paths of all the diverse members of the community. This diversity is not unique to Mindrölling, but it can help explain Terdak Lingpa's approach in designing the curriculum.

Throughout the constitutional document, Terdak Lingpa demonstrates careful attention to these concerns. He constructs an institution that adheres to the prescribed norms of a good Buddhist monastery while also systematizing and safe-guarding the characteristics of Nyingma practice that were highly valued in Tibetan society and culture. In this way he created a kind of contractual agreement to which future generations of students and teachers should adhere, while allowing for different paths and shifts in context. The primary purpose of the curriculum is to lay out the what and how of education at Mindrölling for teachers and students. Its secondary purpose, although not explicit, appears to be to assure those who might either patronize or criticize the monastery of Mindrölling's distinctive characteristics and qualities. Unlike other examples of constitutional documents that are clearly not meant to stand the test of time, or that are guarded by members of the relevant community, Terdak Lingpa's text is now published and widely available, even to people who have never been to Mindrölling.

The curriculum begins by establishing the importance of study and contemplation as the basis for Buddhist awakening. This demands attending to the whole person of the student. It also demands inculcating basic skills, a proper intellectual attitude that is neither lazy nor rigid, respect for teachers, and the memorization of the foundational Nyingma texts. This early education serves as preparation for the three-part examinations that all students at the monastery must pass, ideally but not necessarily within five years. After the examinations are completed, the curriculum focuses on the distinctive textual, ritual, and practical elements of Mindrölling's educational system while consistently allowing for individual approaches and capacities. It lays out the more specialized courses of study that various types of student might undertake, offering different emphases and lists of texts to guide students in their individual course of practice.

What was a field of merit for Terdak Lingpa? According to the curriculum it was a place of cultivation that was regimented and structured but not one-size-fits all. It was a place where students engaged in study, contemplation and meditation, according to their inclination and capacity. It was a place where rituals were conducted in a careful and particular manner, where the worldly arts were developed, where Nyingma and Mindrölling-specific texts were relied on, where everyone followed the rules, and where the highest caliber students engaged in solitary retreat in a focused and purposeful manner without abandoning the discipline of the monastery.

The constitutional document and the curriculum it contains implicitly suggest that Terdak Lingpa was aware that if Mindrölling were to be associated with longstanding perceptions of Nyingma practitioners as lax and corrupt, the institution he had founded might not be perceived as a worthy object of patronage and therefore might not survive. On the other hand, he was committed to maintaining the highly valuable expertise for which his lineage was known.

Subtly, the curriculum places the onus of establishing of Mindrölling's collective worthiness onto its individual members. In that sense, it transfers attention from the monastery's most visible and famous members, such as the author of the document, Terdak Lingpa and his family members, onto the nameless mass of monks of the past, present, and future. According to the curriculum, it is the students, and not only the famous founders and teachers, who embody Mindrölling's potential as a fertile field of Buddhist cultivation and awakening. Therefore the students can also render Mindrölling "worthy of praise." The contractual nature of the curriculum makes it the students' responsibility to act in accordance with the structured yet flexible guidelines Terdak Lingpa lays out. The document effectively defines what it means to be a member of Mindrölling. 
Acknowledgments: Many people have contributed to and supported my research for this article and the larger project to which it relates. In particular, I wish to thank to Lama Gyurme, Khenpo Tsegyal, and Rinchen Dorji. I'd also extend warm thanks to Annabella Pitkin for reading and responding to early drafts. Thanks to Michael Sheehy and Joshua Schapiro for organizing this special issue of the journal and for offering editorial guidance at every turn. I'm also grateful for support from Bard College that allowed me to conduct the necessary field research. Any mistakes or misinterpretations are my own.

Conflicts of Interest: The author declares no conflict of interest.

\section{References}

Austin, J. L. 1975. How to Do Things with Words. Cambridge: Harvard University Press.

Bodhi, Bhikkhu. 2005. In the Buddha's Words: An Anthology of Discourses from the Pali Canon. Boston: Wisdom Publications.

Bourdieu, Pierre. 1977. Outline of a Theory of Practice. Translated by Richard Nice. Cambridge: Cambridge University Press.

Bourdieu, Pierre, and Jean-Claude Passeron. 1990. Reproduction in Education, Society and Culture. Translated by Richard Nice. London: Sage.

Bstan pa'i sgron me. 1992. O rgyan Smin Grol Gling gi Dkar Chag. Xining: Krung go'i bod kyi shes rig dpe skrun khang.

Cabezón, José Ignacio. 1997. The Regulations of a Monastery. In Religions of Tibet in Practice. Edited by Donald S. Lopez. Princeton: Princeton University Press, pp. 335-51.

Cuevas, Bryan. 2003. The Hidden History of the Tibetan Book of the Dead. Oxford: Oxford University Press.

Dalton, Jacob. 2002. The Uses of the Gdongs pa 'dus pa'i dos in the Development of the Rnying-ma School of Tibetan Buddhism. Ph.D. dissertation, University of Michigan, Ann Arbor, MI, USA.

Dalton, Jacob. 2016. The Gathering of Intensions: A History of a Tibetan Tantra. New York: Columbia University Press.

Dhondup, Yangdon. 2013. Rules and Regulations of the Reb kong Tantric Community. In Monastic and Lay Traditions in North-Eastern Tibet. Edited by Yangdon Dhondup, Ulrich Pagel and Geoffrey Samuel. Leiden: Brill, pp. 117-40.

Dreyfus, Georges. 2003. The Sound of Two Hands Clapping: The Education of a Tibetan Buddhist Monk. Berkeley and Los Angeles: University of California Press.

Dudjom Rinpoche, Jikdrel Yeshe Dorje. 1991. The Nyingma School of Tibetan Buddhism: Its Fundamentals and History. Edited by Gyurme Dorje and Matthew Kapstein. Boston: Wisdom Publications, p. 826.

Ellingson, Ter. 1990. Tibetan Monastic Constitutions: The bCa yig. In Reflections on Tibetan Culture: Essays in Memory of Turrell V. Wylie. Edited by Lawrence Epstein and Richard F. Sherburne. Lewiston: The Edward Mellen Press, pp. 205-29.

Gter bdag gling pa. 1977. Collected Religious Instructions of Gter-bdag-gling-pa-'gyur-med-rdo-rje. Dehra Dun: D.G. Khochen Rinpoche.

Gyatso, Janet. 2015. Being Human in a Buddhist World: An Intellectual History of Medicine in Early Modern Tibet. New York: Columbia University Press.

Gyurme, Lama. 2016. Personal communication, over telephone between New York and Santa Fe, November.

Jansen, Berthe. 2015. The Monastery Rules: Buddhist Monastic Organization in Pre-Modern Tibet. Ph.D. dissertation, Leiden University, Leiden, Holland.

Jansen, Berthe. 2016. Monastic Guidelines (bCa' yig): Tibetan Social History from a Buddhist Studies Perspective. In Social Regulation: Case Studies from Tibetan History. Edited by Jeannine Bischofff and Saul Mullard. Leiden and Boston: Brill, pp. 64-98.

Karmay, Samten. 1998. The Ordinance of Lha Bla-ma Ye-shes-'od. In The Arrow and the Spindle: Studies in History, Myths, Rituals and Beliefs in Tibet. Kathmandu: Mandala Books.

Mills, Martin. 2010. Identity, Ritual and State in Tibetan Buddhism: The Foundations of Authority in Gelukpa Monasticism. London and New York: Routledge.

Ngag dbang blo bzang rgya mtsho. 1975. Rgya bod hor sog gi mchog dman bar pa rnams la 'phrin yig snyan ngag tu bkod pa rab snyan rgyud mang (Letters to various notables of China, Tibet, and Mongolia written by the Fifth Dalai Lama). Thimpu: Kunsang Tobgay.

Schaeffer, Kurtis. 2013. The Fifth Dalai Lama. In The Tibetan History Reader. Edited by Kurtis Schaeffer and Gray Tuttle. New York: Columbia, pp. 348-62. 
Schopen, Gregory. 2004. Buddhist Monks and Business Matters: Still More Papers on Monastic Buddhism in India. Honolulu: University of Hawai'i Press.

Schopen, Gregory. 2007. The Buddhist Bhiksu's Obligation to Support his Parents in Two Vinaya Traditions. Journal of the Pali Text Society 29: 107-36.

Sorensön, Per, and Guntram Hazod. 2007. Rulers on the Celestial Plains: Ecclesiastic and Secular Hegemony in Medieval Tibet: A Study of Tshal Gung-Thang. Vienna: Osterreichische Akademie der Wissenschaften.

Sur, Dominic. 2017. Constituting Canon and Community in Eleventh Century Tibet: The Extant Writings of Rongzom and His Charter of Mantrins (ngags pa'i bca' yig). Religions 8: article 40. [CrossRef]

Townsend, Dominique. 2012. Materials of Buddhist Culture: Aesthetics and Cosmopolitanism at Mindroling Monastery. Ph.D. dissertation, Columbia University, New York, NY, USA.

Townsend, Dominique. 2016. Buddhism's Worldly Other: Secular Subjects of Tibetan Learning. Himalaya, the Journal for the Association of Nepal and Himalayan Studies 36: 130-44.

Tsegyal, Khenpo. 2017. Personal communication at Mindrölling Monastery in Clement Town, Dehradun, India, June.

(C) 2017 by the author. Licensee MDPI, Basel, Switzerland. This article is an open access article distributed under the terms and conditions of the Creative Commons Attribution (CC BY) license (http:/ / creativecommons.org/licenses/by/4.0/). 